
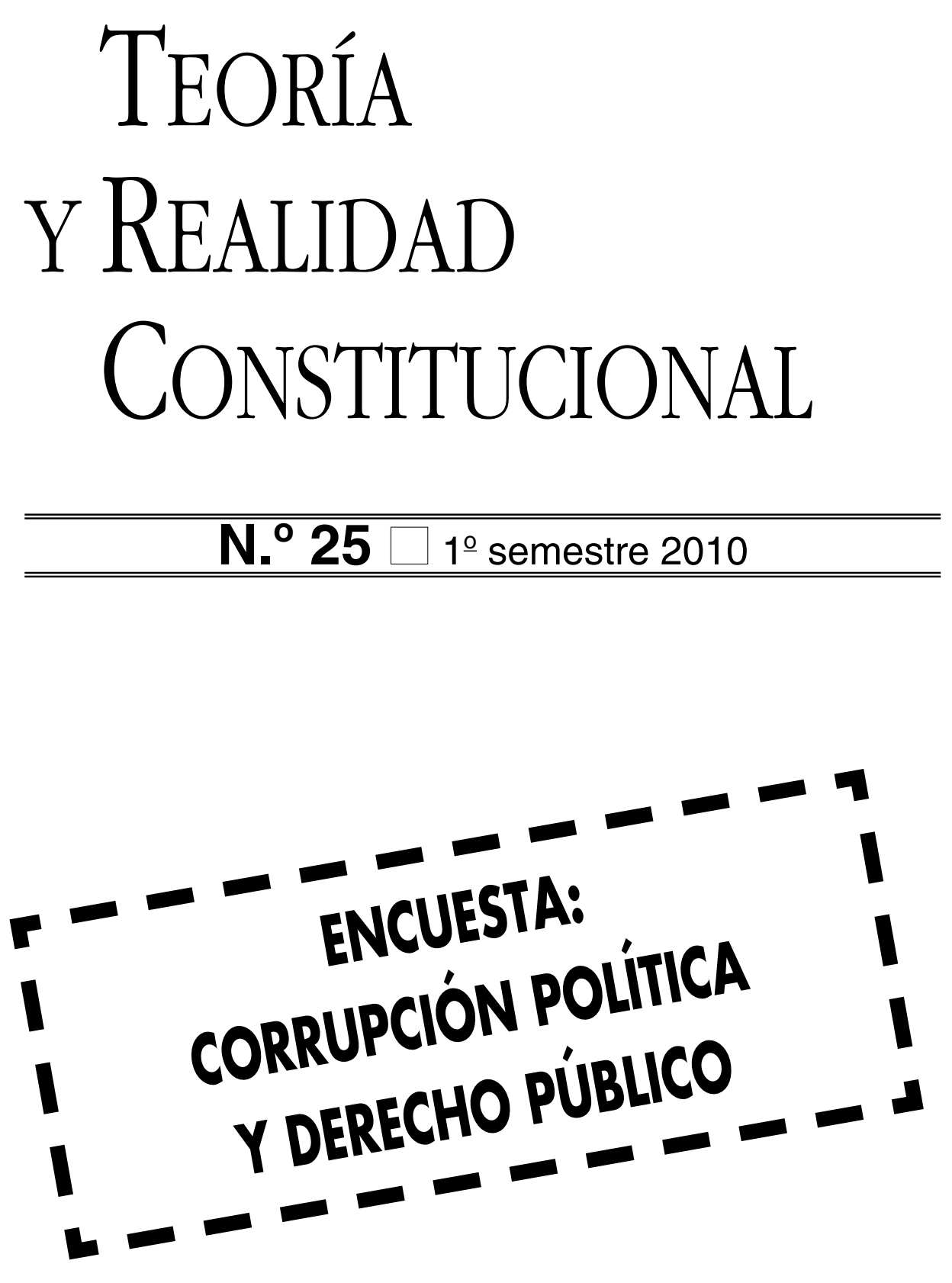


\title{
¿CUESTIÓN DE DERECHOS? EL CONSEJO DE ESTADO ANTE LOS RETOS DEL ABORTO
}

\author{
BLANCA RODRÍGUEZ RUIZ \\ Profesora Titular de Derecho Constitucional \\ Universidad de Sevilla
}
SUMARIO
I. Introducción.
II. El Consejo de Estado y el diálogo entre instituciones sobre la exposición de mo- tivos y los informes de impacto de gé- nero.
III. Del conflicto de derechos a la concilia- ción de intereses. El Consejo de Estado ante la prevención como estrategia.
IV. Reenfocar el aborto desde su dimensión social.

\section{INTRODUCCIÓN}

La Ley Orgánica de salud sexual y reproductiva y de la interrupción voluntaria del embarazo ha introducido un cambio radical en la concepción del aborto dentro de nuestro ordenamiento jurídico. Con ella hemos pasado de un sistema de indicaciones a uno de plazos, de contemplar el aborto como un hecho punible, excepto en tres supuestos legalmente despenalizados, a regularlo en el contexto de una ley que garantiza la posibilidad de acceder a él durante un cierto plazo de tiempo y bajo condiciones determinadas, más allá del cual y de las cuales el aborto seguirá sometido al derecho penal. El objetivo no es otro que desarrollar una nueva estrategia ante el incesante incremento del número de abortos ${ }^{1}$, consistente en encararlo desde una perspectiva principalmente preventiva en lugar de punitiva, siguiendo en esta línea el

1 Véanse los datos proporcionados por el Ministerio de Sanidad y Consumo en su informe de 2008 (http://www.msc.es/profesionales/saludPublica/prevPromocion/embarazo/home.htm\#datos). 
camino marcado ya en los años noventa del pasado siglo por Alemania, y refrendado por el Tribunal Constitucional alemán (Sentencia de 28 de mayo de 1993 - BVergGE 88, 203). Así, y aun sin desplazar por completo al derecho penal, la nueva regulación del aborto reduce su ámbito de actuación, convirtiéndolo en la excepción, en la ultima ratio, al tiempo que suaviza las penas previstas para los supuestos en que el aborto sigue siendo punible. La nueva ley es, en fin, el resultado de la necesidad de hacer frente al fracaso de la legislación punitiva anterior, y a la inseguridad jurídica que rodea su aplicación práctica, así como el fruto de la experiencia de que la estrategia penal no es eficaz para atajar el alto índice de abortos.

Tan profundo como el cambio de perspectiva que opera la nueva regulación del aborto son sus implicaciones de género. Con ella pasamos de criminalizar el aborto, excepto en algunos supuestos predefinidos como tolerables, a garantizar a las mujeres la capacidad de decidir sobre la continuación de su embarazo durante las primeras catorce semanas de gestación, sin que el derecho permita al Estado intervenir en los motivos de su decisión. La mujer gestante pasa así de ser sujeto pasivo de la regulación del aborto a asumir el papel de sujeto activo en la decisión sobre la continuidad de su embarazo. Se asume así como punto de partida la autonomía de las mujeres, nuestra capacidad de auto-normarnos. Ciertamente, lo anterior no equivale a abandonar la protección del feto, pero sí se encuentra en el trasfondo del cambio de estrategia en su protección. En la nueva regulación, la represión cede protagonismo a la prevención en la misma medida en que la protección del feto se lo cede al respeto de la autonomía de las mujeres, de nuestra capacidad de tomar decisiones sobre nuestro proyecto vital. En un análisis más profundo, la nueva regulación del aborto conecta la protección del feto al respeto de la autonomía de la mujer gestante, asume la relación de dependencia que une al feto con quien lo gesta, haciéndose cargo de la conexión de los destinos de ambos, de la dificultad, y del sinsentido, de proteger al uno frente al otro. Renuncia así, durante un periodo en el que esa conexión aparece como inexorable, a oponer los intereses del feto y de la mujer gestante, a concebir su relación en términos de conflicto, apostando más bien por canalizar la tutela del primero a través del respeto y la tutela de los intereses de la segunda. Y si este giro en la percepción del aborto es importante, aún lo es más, para que pueda efectivamente imponerse, que nuestras instituciones y que la ciudadanía lo asuman en toda su profundidad. Cualquier análisis de la oportunidad y de la legitimidad constitucional de la nueva regulación del aborto deberá tomar conciencia de la profundidad del cambio de paradigma que la inspira, y ser coherente con los nuevos parámetros. Es pues crucial que entre las instituciones del Estado, y entre éstas y la ciudadanía, se abran canales de comunicación fluidos que permitan transmitir y asumir el contenido y el sentido último de la reforma de la regulación del aborto llevada a cabo por nuestros representantes políticos.

Sin duda ha habido comunicación con la ciudadanía sobre la nueva regulación del aborto. Sospecho, con todo, que esa comunicación no ha sido 
todo lo fluida que hubiese sido deseable. La polémica que circundó su elaboración son prueba tanto de lo primero como de lo segundo. En lo que concierne a la comunicación entre instituciones, el dictamen del Consejo de Estado al Anteproyecto de ley (Ref. 1.384/2009) ofrece igualmente luces y sombras. El Consejo de Estado ha jugado sin duda un papel importante en el debate en torno a un proyecto de ley tan polémico como el de la nueva regulación del aborto. En una concepción deliberativa de la democracia es crucial que nuestros representantes políticos establezcan canales de diálogo, con la ciudadanía y con otras instituciones y que hagan uso de esos cana$l^{2}{ }^{2}$. Estos pueden ser especialmente fructíferos si no están presididos por la lógica de la confrontación, el control y la depuración del ordenamiento jurídico, sino por la del intercambio de perspectivas sobre la oportunidad política, la calidad técnica y la legitimidad constitucional de una norma. Lo cual contribuye a enriquecer el contenido democrático-deliberativo de la labor legislativa de nuestros representantes.

\section{EL CONSEJO DE ESTADO Y EL DIÁLOGO ENTRE INSTITUCIONES: SOBRE LA EXPOSICIÓN DE MOTIVOS Y LOS INFORMES DE IMPACTO DE GÉNERO}

Es indudable la importancia del dictamen del Consejo de Estado al Anteproyecto de ley orgánica de salud sexual y reproductiva y de interrupción voluntaria del embarazo (Ref. 1.384/2009). Esa importancia es especialmente visible en la incorporación al texto de la ley, sea por el Gobierno o por el Parlamento, de propuestas que el Consejo formulara en su dictamen, y que han versado sobre los aspectos más controvertidos del proyecto, como el proceso de información a la mujer gestante previo al aborto, la edad a la que ésta puede prestar su consentimiento y la objeción de conciencia médica.

El Consejo de Estado es consciente del papel democrático de sus dictámenes sobre Anteproyectos de ley. Y es consciente también de la importancia que en democracia tiene, más genéricamente, establecer instancias de diálogo, tanto entre las instituciones del Estado como entre éstas y la sociedad civil. En este sentido, uno de los aspectos más llamativos de su dictamen al Anteproyecto de ley orgánica de salud sexual y reproductiva y de la interrupción voluntaria del embarazo, es la importancia que éste otorga a la Exposición de Motivos, a su papel como texto transmisor de las intenciones del legislador y

2 Así, HABERMAS, J., The Structural Transformation of the Public Sphere, Polity Press, Cambridge, 1989; NINO, C.S., The Construction of Deliberative Democracy, Yale University Press, New-Haven-London, 1996; DRYZEK, J.S., Deliberative Democracy and Beyond. Liberal, Critics, Contestations, Oxford University Press, Oxford-New York, 2000; BENHABIB, S., "Toward a Deliberative Model of Democratic Legitimacy", en Democracy and Difference, cit. págs. 67-94. 
de comunicación en lenguaje no normativo entre éste y las demás instituciones, pero sobre todo entre éste y la ciudadanía.

Lejos de convertirla en irrelevante, la falta de normatividad de la Exposición de Motivos realza su importancia retórica y política, y aunque la convierte en inmune a parámetros de corrección técnica, o de legitimidad constitucional, la somete a criterios de oportunidad y responsabilidad. Sobre la Exposición de Motivos recae una parte importante del peso de justificar la oportunidad política y jurídica de la norma. Y entiende el Consejo de Estado que sobre ella recae la responsabilidad de justificar esa oportunidad en términos integradores, en términos que mantengan en lo posible la cohesión social y eviten manifestaciones polémicas. Esto es especialmente importante en el marco de cuestiones ideológicamente controvertidas, como es precisamente el caso de la regulación del aborto. Ciertamente, no se le puede pedir al gobierno que desarrolle su labor normativa sin manifestar su posicionamiento político. Sí le pide el Consejo de Estado, sin embargo, que sea prudente y evite "herir sentimientos cuyo respeto es imprescindible al permanente proceso de integración que da vida a la comunidad política" (pág. 63). Reconoce así la función comunicadora de las intenciones del legislador que desempeña la Exposición de Motivos, al tiempo que orienta esa función hacia la integración de la ciudadanía y le exhorta a que evite polémicas y divisiones. Entiende el Consejo de Estado que asumir esa responsabilidad obliga al gobierno a informar a la ciudadanía de forma fidedigna sobre el contenido de la norma, sin aderezar esa información de connotaciones ideológicas o de declaraciones de principios que por su carácter polémico pudieran resultar distorsionantes para su interpretación y aplicación.

E1 Consejo de Estado llama así la atención sobre la importancia de convertir a las Exposiciones de Motivos de las leyes en instrumentos, no sólo de comunicación con la ciudadanía, sino de cohesión social. Esta crítica debe hacernos reflexionar sobre el papel del legislador como representante democrático de toda la ciudadanía. Hacerlo es especialmente importante en el marco de cuestiones polémicas, susceptibles de provocar divisiones sociales, y especialmente oportuno en el contexto de la confrontación partidista en que vivimos inmersos.

En este contexto el Consejo conmina al legislador, y al gobierno en cuanto pre-legislador, a erigir las Exposiciones de Motivos en canal de comunicación con toda la ciudadanía, de transmisión de su papel de representantes políticos de la ciudadanía en su conjunto más allá de divisiones políticas partidistas. Más cuestionable me parece el afán del Consejo de mantener la asepsia ideológica del legislador hasta el punto de limitar su capacidad de explicar la intención que subyace a la elaboración de las normas. De lo contrario, argumenta el Consejo, se corre el riesgo de convertir a la norma en rehén de esa intención original, dificultando su capacidad de adaptación a situaciones futuras. Para evitar este resultado es conveniente, sugiere, "separar la lógica interna del texto y de su contexto — lo que se ha 
denominado canon de inmanencia - de lo que fuese la primitiva intención política de los autores de la ley" (págs. 63-64). Sin cuestionar la prevalencia del canon de inmanencia, y sin pretender que la Exposición de Motivos de las normas jurídicas condicione su interpretación y aplicación futuras, no cabe duda de que dar a conocer la intención política de sus autores es importante, no ya como criterio interpretativo de la norma, aunque también desempeñe un papel en este terreno, sino sobre todo como elemento de una comunicación que se quiere fluida entre el legislador y la ciudadanía, asî como entre el legislador y las demás instituciones del Estado. Entiendo que estas críticas del Consejo de Estado son una respuesta no tanto al hecho de que la Exposición de Motivos de la nueva regulación del aborto tansmita cuál era la intención del gobierno al redactar el Anteproyecto de ley, sino, de nuevo, a la retórica afectiva y potencialmente polémica con que justifica la iniciativa legislativa. En todo caso, los reproches del Consejo de Estado no hacen sino enfatizar el papel de las Exposiciones de Motivos como canal de comunicación entre el legislador, la ciudadanía y las instituciones del Estado, realzando de esta forma su lugar en el proceso legislativo democrático.

En esa misma lógica comunicativa, el dictamen del Consejo de Estado valora positivamente la incorporación al expediente del Anteproyecto, no sólo de los informes preceptivos que deben acompañarle, sino de los datos y criterios proporcionados por los estudios previos sobre la oportunidad y necesidad de la norma, en particular de los informes de la Subcomisión creada en el seno de la Comisión de Igualdad del Congreso y del Comité de Personas Expertas constituido en el Ministerio de Igualdad. En concreto, el Consejo valora positivamente que la incorporación de estos últimos tenga contenido sustantivo y no se reduzca a un mero encadenamiento de trámites, respondiendo así a la finalidad del proceso de elaboración normativa, que no es sino la de recabar, en clave deliberativa, cuantos estudios y consultas se estimen convenientes para garantizar el acierto y la legalidad del texto ${ }^{3}$.

Llama la atención, en contraste con lo anterior, la escasa atención que el dictamen del Consejo de Estado presta al informe de impacto de género que acompañó al Anteproyecto de Ley de interrupción voluntaria del embarazo, conforme a lo establecido en la Ley 30/2003, de 13 de octubre, sobre medidas para incorporar la valoración del impacto de género en las disposiciones normativas que elabore el Gobierno. El dictamen se limita a mencionar que dicho informe aparece incorporado en el expediente. Tan escasa atención es especialmente llamativa, no sólo a la vista de la atención que se presta a otros informes, sino también, y sobre todo, habida cuenta de la actitud crítica que en ocasiones anteriores el Consejo de Estado ha mantenido respecto a los informes de impacto de género. De ella encontramos buena muestra en el

3 En esa misma clave deliberativa, señala el Consejo, debieran haberse incorporado al expediente las transcripciones o, cuanto menos, un testimonio de las comparecencias de diferentes colectivos ciudadanos ante la Subcomisión parlamentaria, más allá de la mera relación nominal de los mismos. 
Dictamen del Consejo al Anteproyecto de Ley Orgánica para la igualdad efectiva de mujeres y hombres (Ref. 803/2006, de 22 de junio). El Consejo de Estado aprovechó esa oportunidad para recordar cuál debe ser el contenido de los informes de impacto de género, que éstos no pueden limitarse a valorar un Anteproyecto de Ley desde la perspectiva del principio de igualdad contenido en los Artículos 14 y 9.2 de la Constitución, esto es, desde la perspectiva del respeto de la igualdad de trato o de la igualdad de oportunidades en el marco del sector concreto objeto de regulación. Así concebida, la evaluación del impacto de género de un proyecto normativo se reduciría a un análisis de la conformidad de éste con el principio constitucional de igualdad. El objetivo de la evaluación del impacto de género es, sin embargo, distinto y más ambicioso. De lo que se trata con ellos es de ir más allá de un juicio de constitucionalidad para indagar las posibles consecuencias negativas que puedan derivarse de un instrumento normativo que, de forma más o menos directa, y con independencia de su intencionalidad, pudieran favorecer situaciones de discriminación. Se trata, en definitiva, de evaluar los posibles efectos colaterales que una determinada normativa pueda tener sobre las relaciones entre los sexos, y de hacerlo, además, desde una perspectiva transversal, superando las visiones sectoriales de la realidad y de las políticas de igualdad destinadas a regularla.

En líneas generales, los informes de impacto de género no han respondido a esta finalidad. Con demasiada frecuencia, como recordaba el Consejo de Estado en su Dictamen al Anteproyecto de Ley Orgánica para la igualdad efectiva de mujeres y hombres, "el informe en cuestión se limita a un escueto párrafo en el que se afirma — sin mayor razonamiento- que la norma proyectada afecta por igual a hombres y a mujeres. El Consejo de Estado ha llamado la atención en distintas ocasiones sobre la futilidad de un informe de tal alcance, apuntando el contenido que ha de dársele en función del fundamento de su exigencia o censurando su carácter escueto o estereotipado, frente a la evidencia de un impacto sobre el que no se informa" (Ref. 803/2006). En efecto, Anteproyectos de leyes de tanta incidencia en las relaciones entre los sexos como puede ser la que modificó el Código Civil en materia de derecho a contraer matrimonio para reconocer la validez de los matrimonios del mismo sexo (Ley 13/2005, de 1 de julio), la que modificó el Código Civil y la Ley de Enjuiciamiento Civil en materia de separación y divorcio (Ley 15/2005, de 8 de julio), la ley de educación (Ley Orgánica 2/2006, de 3 de mayo), o la ley de técnicas de reproducción asistida (Ley 14/2006, de 26 de mayo), Anteproyectos de leyes como las anteriores, decía, fueron acompañados por un informe en el que lacónicamente se negaba que dichas leyes fuesen a tener de impacto de género alguno ${ }^{4}$. Todo ello más allá

4 Para un análisis crítico de los informes de impacto de género que acompañaron a estos y otros anteproyectos de leyes, así como de la inaccesibilidad de los mismos, consúltese Pujol ALGaNs, C. (dir.), Estudio del impacto de género en las leyes, estudio presentado en el XVIII Congreso estatal de mujeres abogadas, Almería, 11-13 de noviembre de 2005. 
de los numerosos casos de incumplimiento de la obligación de elaborar dicho informe ${ }^{5}$, aun tratándose de leyes con un impacto de género previsible ${ }^{6}$, como la Ley de Presupuestos Generales del Estado, que hasta 2009 no fue acompañada de dicho informe.

Pues bien, frente a la actitud crítica mantenida en otras ocasiones, el Consejo de Estado se limita a dar por bueno el informe de impacto de género aportado al Anteproyecto de Ley Orgánica de salud sexual y reproductiva y de la interrupción voluntaria del embarazo. Puede que el cambio de actitud se deba a que, en este caso, el informe de impacto de género respondía efectivamente al sentido que debe tener un informe de este tipo, tal y como aparece establecido en la propia doctrina del Consejo. No he podido tener acceso a dicho informe, por lo que sólo puedo especular sobre esta posibilidad. De ser este el caso, con todo, nos encontraríamos ante una mejora técnica en la redacción de informes de impacto de género de tanta importancia que resulta llamativo que el Consejo no se detenga a mencionarla. Pero es que, además, de su dictamen sólo se desprende que dicho informe contenía datos estadísticos sobre actitudes sexuales y anticonceptivas de la población española. El impacto de género de la regulación del aborto va sin embargo más allá de lo que indican esos datos. Tomarnos en serio su análisis implica evaluar la repercusión que la nueva regulación del aborto puede llegar a tener en las relaciones entre los sexos. Implica, por ejemplo, evaluar en qué medida la nueva regulación mejorará la corresponsabilidad reproductiva y parental a través de la educación, o cuáles son las probabilidades de que con ella se reduzca tanto el número de embarazos no deseados como el porcentaje de abortos, y todo ello no ya desde la perspectiva del respeto a la vida, sino desde una perspectiva de género - desde la perspectiva, esto es, de la repercusión que la ley puede tener en las relaciones entre los sexos.

Ciertamente, sin conocer dicho informe, no es posible emitir un juicio, ni sobre él, ni sobre su breve consideración por parte del Consejo de Estado. Sí es obligado criticar, precisamente, la inaccesibilidad de dichos informes, que en el mejor de los casos los reduce a instrumentos de comunicación entre instituciones del Estado, privando a la ciudadanía de la posibilidad de acceder a las conclusiones de su análisis y someterlas a juicio crítico. Esto es lógicamente tanto más importante cuanto mayor sea el impacto de género que previsiblemente pueda tener una determinada normativa. Y si toda regulación del

5 Según la Plataforma Impacto de Género YA, los Anteproyectos del 11,5\% de las leyes aprobadas a fecha de 1 de octubre de 2005 no fueron acompañados de ese preceptivo informe (http://impactodegeneroya.blogia.com).

6 Es el caso, por ejemplo, de la Ley 1/2004, de 21 de diciembre, de horarios comerciales, cuya aplicación afecta a la conciliación de la vida laboral y familiar de consumidores/as y de trabajadores/as de pequeños y medianos comercios. Un análisis de impacto de género obligaba a analizar, como poco, la feminización de este sector. Sobre esta y otras leyes aprobadas sin informe de impacto de género, véase Pujol ALGANS, C. (Dir.), Estudio del impacto de género en las leyes, cit. 
aborto tiene necesariamente un impacto de género importante, la Ley Orgánica de salud sexual y reproductiva y de la interrupción voluntaria del embarazo introduce una nueva regulación del aborto cuyo impacto de género es, como ya al principio señalaba, potencialmente inmenso.

\section{DEL CONFLICTO DE DERECHOS A LA CONCILIACIÓN DE INTERESES. EL CONSEJO DE ESTADO ANTE LA PREVENCIÓN COMO ESTRATEGIA.}

La novedad central de la nueva regulación del aborto, el eje sobre el que toda ella pivota, consiste, como hemos visto, en abordar la problemática del aborto desde una perspectiva preventiva antes que punitiva. La estrategia, en este sentido, es doble. Se persigue, ante todo, evitar embarazos no deseados, mediante el desarrollo de una política de formación, información y educación sexual. Ante la consumación de un embarazo no deseado, o no planificado, la estrategia de la ley para prevenir abortos consiste en informar a la mujer gestante de las posibilidades que el Estado social pone a su disposición si desea seguir adelante con el embarazo, respetando siempre su autonomía para decidir durante las primeras catorce semanas de gestación. A partir de ahí, la autonomía de la mujer gestante cede ante la obligación del Estado de proteger la vida no nacida y el aborto vuelve a ser punible, salvo durante las primeras veintidós semanas de gestación, en supuestos de riesgo para la vida o la salud de la embarazada o de graves anomalías en el feto, así como en cualquier momento del embarazo, cuando se detecten en el feto anomalías incompatibles con la vida; todo ello sobre la base de informes emitidos por dos médicos especialistas, distintos del que practique la intervención. En este último caso, es precisa la confirmación por un comité clínico.

Pues bien, el dictamen del Consejo de Estado no acaba de tomar plena conciencia del giro que introduce en el tratamiento del aborto en nuestra regulación. Ciertamente, y en línea de principio, el Consejo de Estado asume el protagonismo de lo preventivo. Valora así positivamente las medidas previstas en la ley de cara a la inserción de la educación sexual en los currícula escolares. Nos encontramos, afirma el Consejo, ante un elemento imprescindible de la instrucción adecuada a que tienen derecho los y las menores. Y aunque en principio dichas medidas podrían entrar en colisión con el derecho fundamental de los padres a elegir la formación religiosa y moral que desean para sus hijos e hijas, reconocido en el artículo 27.3 de la Constitución, el Consejo descarta que este último derecho pueda ejercerse a costa de la educación adecuada a que tienen derecho los menores, en virtud del artículo 27.1 de la Constitución. Como parte de una educación adecuada, puntualiza con todo el Consejo, citando jurisprudencia del Tribunal Europeo de Derechos Humanos, la educación sexual debe respetar el equilibrio y la salud de niñas, niños y adolescentes, lo cual requiere que se imparta en términos objetivos y científicos que excluyan toda tendencia al adoctrinamiento, a la exaltación del 
sexo o a la incitación a alumnas y alumnos a dedicarse precozmente a prácticas peligrosas para su desarrollo.

El objetivo es, en definitiva, poner la educación sexual al servicio del conocimiento, por parte de niñas, niños y adolescentes, de sí mismos y de las dinámicas relacionales que articulan su medio social, de cara a fomentar en ellos el desarrollo de una autonomía responsable. Pues bien, en opinión del Consejo de Estado, la regulación de la educación sexual propuesta en la Ley Orgánica de salud sexual y reproductiva y de la interrupción voluntaria del embarazo (en el Anteproyecto de la misma) se acoge a las exigencias del artículo 27 de la Constitución. En opinión del Consejo de Estado, con todo, su redacción podría haber estado más abiertamente orientada a promover la autonomía y el equilibrio de quienes reciben educación sexual. Propone el Consejo la fórmula de redacción danesa, avalada por el Tribunal Europeo de Derechos Humanos (Caso Kjelsen, Busk y Pedersen c. Dinamarca, Sentencia TEDH 1976/5, de 7 de diciembre), en la que se enfatiza el respeto, el autoconocimiento, el equilibrio y la responsabilidad (Decreto de 25 de junio de 1970, artículo 1). Es ésta una fórmula que ciertamente capta con acierto y elegancia el espíritu que debe inspirar la educación sexual de los menores. Seguramente nuestra legislación habría ganado en calidad si la hubiese incorporado. No ha sido asī ${ }^{7}$ Queda aún por ver, con todo, hasta qué punto la fórmula danesa se asume en su desarrollo reglamentario y su aplicación práctica. Y es que la operatividad de las previsiones legislativas en materia de educación sexual dependerá, en última instancia, de los términos en que se articule su efectiva implementación. Tras situar la educación sexual a la cabeza de las políticas públicas para la prevención de abortos, corresponde a los poderes públicos el desarrollo de una política adecuada de educación sexual que impida que el compromiso con ésta última se quede en una mera declaración de principios.

Si la educación sexual es el eje de las políticas preventivas de embarazos no deseados, en el centro de las políticas preventivas de aborto ante la consumación de un embarazo no deseado se sitúa la obligación de informar a la mujer gestante sobre prestaciones y ayudas disponibles, y sobre los derechos que la asisten, tanto si se opta por la continuidad del embarazo como por la interrupción del mismo, y ello como requisito previo a que ésta preste su consentimiento a dicha interrupción. Esta obligación de informar no encuentra su

7 El Proyecto de Ley del Gobierno incorporó en su artículo 9 c) una breve referencia a que la educación sexual debe permitir un desarrollo armónico de la sexualidad "acorde con la personalidad de los jóvenes", expresión que fue sustituida por una referencia, sin duda más abstracta, a "las características de las personas jóvenes", durante la tramitación del Proyecto en el Congreso de los Diputados. Debe destacarse, por lo demás, la incorporación, también durante la tramitación del Proyecto de Ley en el Congreso, de un apartado f) a ese mismo artículo 9, según el cual «f) En la incorporación de la formación en salud y salud sexual y reproductiva al sistema educativo, se tendrán en cuenta la realidad y las necesidades de los grupos o sectores sociales más vulnerables, como el de las personas con discapacidad proporcionando, en todo caso, a este alumnado información y materiales accesibles, adecuados a su edad". 
razón de ser única, ni siquiera fundamental, en la obligación de los poderes públicos de velar por la salud física y psicológica de la mujer gestante, ante la posibilidad de su inminente decisión de interrumpir su embarazo. Antes bien, la información se convierte en el instrumento principal a través del cual los poderes públicos canalizan su obligación de tutelar la vida del feto, desplazando a las políticas represivas articuladas a través del Código Penal.

Renunciar al derecho penal a favor de políticas preventivas implica contemplar la problemática del aborto desde una perspectiva radicalmente distinta. Implica, en concreto, renunciar a contemplar el aborto desde la perspectiva de un conflicto de derechos entre la mujer gestante y el feto, entre la obligación constitucional del Estado de respetar la autonomía, la integridad física, la intimidad de la primera y su obligación también constitucional de proteger la vida del feto, aunque en este caso no exista titular alguno del derecho a la vida y ésta deba ser protegida a costa de la única persona capaz de proporcionarla, a saber, la mujer gestante. Lejos de acogerse a esa lógica conflictual, la regulación del aborto en clave preventiva asume la unión de los destinos del feto y de la mujer gestante tratando, no de oponerlos, sino de armonizarlos, canalizando la protección del feto a través del respeto de la autonomía de la madre gestante, renunciando a proteger la vida del primero en contra de la voluntad de la segunda. En este sentido, como afirmaba ya la Exposición de Motivos del Anteproyecto, la nueva regulación apuesta por canalizar la protección de la vida prenatal a través de la voluntad de la mujer, y no contra ella, una política que el Consejo de Estado suscribe y asume como válida. En efecto, afirma el Consejo, la tutela del feto "no puede pretenderse ni conseguirse contra la madre gestante, sino con la madre.. Ello es así al menos durante las primeras 14 semanas de embarazo. Durante ese periodo, que el Consejo de Estado propuso reducir a 12 semanas, el feto carece de "vida independiente de la madre", y aunque éste constituye "en todo momento un tertium sustantivo digno de protección, su unión con la madre es tal que parece lógico que sea determinante la libre opción de ésta", siempre que se satisfagan ciertas condiciones que más abajo abordaremos.

El Consejo de Estado suscribe pues la nueva aproximación al aborto, su planteamiento preventivo, así como la correspondiente visión de la madre gestante y del feto desde una perspectiva relacional, que asume la dependencia de éste respecto de la primera. Y sin embargo al Consejo de Estado le cuesta sustraerse a una aproximación conflictual al aborto. Que le cuesta es evidente, para empezar, en sus esfuerzos por analizar la nueva regulación del aborto a la luz de la jurisprudencia sentada por el Tribunal Constitucional en su STC 53/1985, de 11 de abril. Esta sentencia analiza la constitucionalidad de los tres supuestos de despenalización del aborto que la actual regulación viene a derogar y lo hace desde la perspectiva de un conflicto de derechos. Ciertamente, la STC 53/1985 contiene los únicos criterios con que hoy contamos para analizar la nueva regulación del aborto, y ciertamente esos criterios han de servir de parámetro para enjuiciar la constitucionalidad de algunos de sus aspectos. Piénsese así en los nuevos supuestos de despenalización del aborto, 
transcurridas las primeras 14 semanas de gestación, cuya constitucionalidad el Consejo de Estado considera indiscutible a la luz, precisamente, de la doctrina sentada por el Tribunal Constitucional en su STC 53/1985. O piénsese, más genéricamente, en la obligación del Estado de tutelar la vida del feto que debe estar presente en toda regulación del aborto. Con todo, el cambio de perspectiva que esta nueva regulación introduce es tan profundo que la anterior doctrina constitucional no alcanza a arrojar suficiente luz sobre su constitucionalidad.

El Consejo de Estado se mueve así entre dos aguas, entre la reticencia a abandonar la retórica del conflicto de derechos, de poca utilidad en el contexto de una política preventiva, y la inclinación a asumir la de la conciliación de intereses que informa el régimen de plazos previsto en la nueva regulación del aborto. Ello le lleva, por ejemplo, a rechazar que el aborto, cuando es lícito, sea también un derecho. Antes bien, lo concibe, no como un derecho, sino como una mera manifestación el agere licere, como una manifestación de la libertad de desarrollar conductas no prohibidas por la ley. La diferencia no es baladí. Ser titular de un derecho va más allá de gozar de libertad para actuar de una determinada manera no proscrita por la ley. Implica, en concreto, que los poderes públicos no pueden limitarse a tolerar una determinada conducta, sin impedirla ni interferir en su desarrollo, manteniéndose, en definitiva, neutral ante ella (STC 11/1981, de 8 de abril, FJ 9). Frente a titulares de derechos, sean éstos fundamentales o no, pero que siempre son, en última instancia, pretensiones frente a los poderes públicos, éstos no sólo tienen la obligación negativa de la neutralidad, sino también la obligación positiva de ofrecer garantías para su ejercicio o su disfrute.

Que a la luz de la jurisprudencia del Tribunal Constitucional no existe derecho fundamental a acceder al aborto lícito parece indiscutible. Tal derecho es, en efecto, difícil de encuadrar en ninguno de los derechos fundamentales reconocidos en nuestro texto constitucional, especialmente en la medida en que éste no reconoce un derecho fundamental a la autonomía personal. Pero me parece también indiscutible que la nueva regulación del aborto no se limita a tolerarlo, sino que concibe el acceso al aborto lícito como un derecho de rango legal. Negar la existencia de un derecho legal al aborto equivale a negar que las mujeres gestantes que desean abortar puedan reclamar del Estado las correspondientes prestaciones médicas previstas en la ley, siendo el caso que el objetivo de la nueva regulación del aborto es, precisamente, garantizar el acceso a estas prestaciones, en el marco de las condiciones por ella establecidas. Distinguir entre los términos reconocer y garantizar, como hace el Consejo de Estado, y conectar sólo el primero con la existencia de un derecho, es un recurso retórico poco plausible - piénsese que nuestra Constitución utiliza ambos términos indistintamente en el contexto de los derechos fundamentales. Y es que reconocer un derecho equivale a asumir la responsabilidad de garantizar las condiciones para su ejercicio. Las reticencias del Consejo de Estado a admitir que la nueva regulación del aborto reconoce a éste como un derecho legal esconden consideraciones sin duda más morales 
que jurídicas. Pero también son expresión de que el Consejo de Estado sigue concibiendo el aborto desde la perspectiva de la descriminalización, concebida a su vez como un desenlace constitucionalmente posible de un enfrentamiento entre derechos fundamentales, no como una posibilidad ya de entrada prevista, regulada y garantizada por ley.

Las reticencias del Consejo de Estado a abandonar la concepción conflictual de los derechos se ponen de manifiesto, también y sobre todo, en su análisis del proceso de información a la mujer gestante previo a la prestación de su consentimiento a la interrupción del embarazo. Al erigir la obligación del Estado de informar a la mujer gestante en instrumento central de tutela de la vida del feto durante las primeras 14 semanas de gestación, nuestro legislador ha optado por renunciar a concebir la vida del feto y la autonomía de la mujer como bienes antagónicos durante ese periodo. Antes bien, ha optado por asumir que la mejor manera de canalizar la tutela de la primera es a través de la decisión autónoma de la mujer gestante de proseguir con su embarazo. Lo cual implica asumir la posibilidad de que la mujer gestante decida autónomamente interrumpir el proceso de gestación. Esta posibilidad revela la centralidad, y lo delicado, del papel que en la nueva regulación del aborto juega ese proceso informativo. La regulación de ese proceso debe ser, de un lado, suficientemente tuitiva de la vida del feto a la luz del artículo 15 de la Constitución; de otro lado, deberá ser respetuosa con la autonomía de la mujer gestante. Todo lo cual desemboca en la cuestión de hasta qué punto el Estado puede intentar influir en la decisión final de la mujer para cumplir con su obligación de tutelar la vida del feto. Ciertamente, la obligación de respetar su autonomía descarta que pueda ejercerse coerción alguna sobre ella, o que el Estado pueda incluso mostrarse favorable a la continuidad del embarazo. Como señala el Consejo de Estado en su dictamen, "no se trata de un consejo, sino de una información". No es fácil, con todo, trazar la línea divisoria entre el consejo y una información de la que se pretende actúe como instrumento al servicio de proteger la vida del feto.

De lo que se trata, en definitiva, es de armonizar dos obligaciones del Estado, a saber, su obligación de respetar la autonomía de la mujer y la de tutelar suficientemente la vida el feto. El dictamen del Consejo de Estado nos ofrece un modelo de armonización distinto del que aparecía previsto en el Anteproyecto de ley. Este se escoraba por ofrecer un mayor nivel de respeto a la autonomía de la mujer gestante, estipulando que se le debe proporcionar información neutra, clara, comprensible y accesible para todas las personas, incluso aquéllas con discapacidad, sobre las ayudas, las prestaciones y los derechos que asisten a la mujer gestante tanto si prosigue con el embarazo y maternidad como en el supuesto de interrupción del embarazo (artículo 17). Por su parte, el Consejo de Estado apostó por ofrecer mayor tutela a la vida del feto. Sin cuestionar que es a las mujeres a quienes corresponde la decisión final sobre la continuidad de su embarazo, la propuesta del Consejo es que los poderes públicos se comprometan con la tutela de la vida del feto hasta el punto de intentar influir en esa decisión. En concreto, tomando 
explícitamente como punto de referencia el modelo alemán, el Consejo cuestiona la constitucionalidad de que la información se proporcione por escrito, de forma estandarizada y neutra. Antes bien, apunta, la información debe ser proporcionada verbalmente, de forma personalizada, en línea con lo previsto en la Ley 41/2002, de 14 de noviembre, reguladora de la autonomía del paciente para cualquier intervención en el ámbito de la salud (artículos 4 y 5). Lejos de ser neutra, añade el Consejo, la información debe estar orientada a animar a la mujer a continuar con el embarazo, a la protección de la maternidad.

La propuesta del Consejo de Estado de que la mujer que opte por la interrupción de su embarazo debe recibir información verbal y personalizada, de acuerdo con lo establecido en la ley de autonomía del paciente, fue asumida por el gobierno y aprobada en sede parlamentaria (artículo 17.4). Conforme a la nueva redacción de la ley, la mujer debe recibir, no sólo información escrita sobre ayudas públicas, derechos y prestaciones vinculados tanto a la interrupción del embarazo como a su continuación, al parto y la maternidad. Deberá recibir además información presencial y personalizada sobre las consecuencias médicas, psicológicas y sociales de la prosecución del embarazo o de la interrupción del mismo. Gobierno y parlamento incorporaron igualmente la propuesta de suprimir el requisito de que la información debe ser neutral. El resultado es un proceso informativo indudablemente más tuitivo de la vida del feto que el inicialmente previsto en el Anteproyecto de ley. La cuestión es hasta qué punto lo es a costa de comprometer la autonomía de la mujer gestante —y efectivamente el modelo alemán ha sido criticado por intrusivo en la intimidad de la mujer, como violador de su dignidad y de su autonomía gulación del aborto.

En principio, la autonomía de la mujer no tiene por qué verse comprometida por el requisito de que la información se transmita de forma verbal. Si asumimos que el contenido de la información es el mismo, su modo de transmisión, verbal o por escrito, es en principio irrelevante desde la perspectiva de la autonomía de la mujer. Dicho esto, y con todo, es cierto que el contacto verbal puede exponer a la mujer gestante al poder implícito de quien se encuentra en situación de autoridad respecto a ella9. Esto es especialmente así en la medida en que la comunicación verbal se pone al servicio de la obligación de modular la información a las circunstancias personales de la mujer receptora de dicha información, todo ello de cara a tutelar la vida del

8 Véase así, por todos, B. RODRÍGUEZ RUIZ y U. SACKSOFSKY, "Gender in the German Constitution", en The Gender of Constitutional Jurisprudence, Beverly Baines and Ruth RubioMarin eds., Cambridge University Press, 2005., págs. 149-173, esp. en 168 y ss.

9 Sobre la alienación de los pacientes en la persona del personal médico, en la medida en que éste posee sobre la primera la autoridad que le otorga controlar los códigos que le permiten definir e interpretar su verdad, véase Michel Foucault, Madness and Civilisation. A History of Insanity in the Age of Reason. Vintage, N. Y., 1988, esp. pág. 276. 
feto. Para empezar, y como el propio Consejo de Estado admite, personalizar la información puede atentar contra la intimidad de la mujer gestante. Pero es que además someter a la mujer gestante a un proceso informativo ajustado a las circunstancias de su propia vida puede convertir el proceso informativo en una medida paternalista, fruto de una percepción de la mujer, no como la persona responsable a que el propio Consejo de Estado se había referido en un momento anterior, sino como una persona incapaz de entender sus propias coordenadas vitales, e incapaz en consecuencia de actuar con responsabilidad y autonomía sobre la base de información objetiva. Todo ello aunque se lograse evitar la intromisión en su intimidad, algo que me parece más difícil que al Consejo de Estado. Las posibilidades de paternalismo son mayores cuanto menos responsable, menos autónoma y más vulnerable aparezca la mujer gestante en el imaginario popular, y en el del personal sanitario, lo que puede abrir la puerta a solapadas prácticas de discriminación de determinados sectores poblacionales. Pero el riesgo de paternalismo está especialmente presente donde la información, además de ser personalizada, se transmite, no de forma objetiva y neutra, sino con una carga ideológica orientada a proteger la maternidad, a condicionar a quien se encuentra ante una decisión vital de tanta importancia y carga emocional como la de continuar o interrumpir un embarazo.

Pues bien, las propuestas del Consejo de Estado en torno al proceso informativo previo a la prestación del consentimiento a un aborto van más allá de lo previsto en la ley de autonomía del paciente y apuntan, precisamente, a que el proceso abandone su neutralidad, para orientarse a la protección de la maternidad y no al fomento de la interrupción voluntaria del embarazo, ofreciendo ayuda a la madre gestante». Siguiendo esta propuesta, el texto de la ley ha abandonado la mención del requisito de la neutralidad. Sin embargo el texto de la ley no ha incorporado la exigencia de que el proceso informativo se oriente a fomentar la maternidad y el rechazo del aborto. Antes bien, y como hemos visto, establece la información verbal y personalizada que se debe prestar a la mujer gestante versa sobre las consecuencias médicas, psicológicas y sociales tanto de proseguir como de interrumpir el embarazo. De este modo, la ley parece haber optado por superar la dicotomía que opone la protección de la maternidad al fomento del aborto, manteniendo su compromiso con la neutralidad, y ello como condición para que sea la mujer quien autónomamente decida sobre la continuidad de su embarazo y asuma las consecuencias de su decisión. La labor del Estado consiste, no en fomentar la maternidad, sino en procurar que esa decisión sea lo suficientemente informada como para poder considerarse efectivamente autónoma.

\section{REENFOCAR EL ABORTO DESDE SU DIMENSIÓN SOCIAL.}

La solución asumida en la nueva regulación del aborto nos invita, en definitiva, a cohonestar la protección de la vida del feto con el respeto de la au- 
tonomía de la mujer gestante como obligaciones compatibles, canalizando la primera a través de la segunda. El reto consiste en mantener la neutralidad, de cara a respetar la autonomía de la mujer, y al mismo tiempo, tutelar la vida del feto, a pesar o precisamente a través de esa neutralidad. Para asumir ese reto es preciso operar un profundo cambio de perspectiva sobre el aborto, un cambio de perspectiva que asuma su dimensión social. Es importante tomar conciencia de que en el trasfondo de un buen número de abortos se encuentran circunstancias sociales que llevan a la mujer a asumir de forma absolutamente prevalente la responsabilidad de cuidar de una nueva vida, una responsabilidad cuyas dificultades y costes tienen profundas raíces sociales. En esta situación, es preciso dirigir los esfuerzos del Estado hacia la creación de un contexto social en que el coste (personal, profesional, económico, emocional) de un proceso de gestación y de la posterior maternidad sea compartido por la mujer gestante, por el futuro padre en su caso, y por la sociedad en su conjunto. La obligación del Estado de tutelar la vida conlleva su responsabilidad de crear prestaciones y servicios que faciliten el desarrollo de una vida nueva, y de informar debidamente sobre ellos a la mujer gestante, en lugar de desplazar hacia ésta el coste social de una nueva maternidad. Es responsabilidad del Estado, en definitiva, crear las condiciones para que el recurso al aborto no actúe como vía de salida ante desigualdades sociales y de género.

A la relevancia del contexto social y de las ayudas públicas en las decisiones sobre la continuidad de un embarazo se refirió el Tribunal Constitucional en su STC 53/1985, de 11 de abril. Al afirmar la constitucionalidad de la descriminalización del aborto eugenésico, el Tribunal Constitucional apuntó que "la situación excepcional en que se encuentran los padres, y especialmente la madre, (viene) agravada en muchos casos por la insuficiencia de prestaciones estatales y sociales que contribuyan de modo significativo a paliar en el aspecto asistencial la situación, y a eliminar la inseguridad que inevitablemente ha de angustiar a los padres acerca de la suerte del afectado por la grave tara en el caso de que les sobreviva" (FJ 11). Este planteamiento del Tribunal Constitucional, ya en 1985, contrasta con la escasa importancia que el Consejo de Estado otorgó al artículo 17.3 del Anteproyecto de Ley Orgánica de salud sexual y reproductiva y de la interrupción voluntaria del embarazo, desde una perspectiva de su constitucionalidad y oportunidad. Este precepto dispone que, en los supuestos en que exista riesgo de graves anomalías en el feto, la mujer recibirá «información por escrito sobre los derechos, prestaciones y ayudas públicas existentes de apoyo a la autonomía de las personas con alguna discapacidad, así como la red de organizaciones sociales de asistencia social a estas personas"

Que el Consejo de Estado haya pasado de puntillas por este precepto es elocuente de hasta qué punto se encuentra aún lejos de reconocer lo que en la problemática del aborto hay de dimensión social. Lo es tanto más cuanto que nos encontramos en un terreno, el del aborto eugenésico, que preocupa especialmente al Consejo de Estado, no ya desde la perspectiva de su consti- 
tucionalidad, que no cuestiona, sino desde la de su conformidad con tratados internacionales, en concreto desde la perspectiva de la Convención sobre los derechos de las personas con discapacidad, aprobada por la Asamblea General de Naciones Unidas el 13 de diciembre de 2006. El aborto eugenésico es, sin duda, una cuestión especialmente delicada, que plantea importantes cuestiones jurídicas y morales, como bien refleja el dictamen del Consejo de Estado. Y es también un terreno en el que la certeza de contar con adecuadas ayudas estatales puede ser especialmente condicionante en la decisión de proseguir con un embarazo y asumir la futura maternidad, como ya subrayó el Tribunal Constitucional en su STC 53/1985. A pesar de ello, el Consejo de Estado no parece reconocer la importancia de que los poderes públicos elaboren un tejido social amable con la maternidad y la paternidad de cara a evitar abortos, eugenésicos o no, y de que informen sobre dicho tejido a la mujer gestante. Antes bien, en su enfoque el aborto se sigue percibiendo como un problema individual de la mujer, como un conflicto entre ésta y el feto, que resuelve comprometiendo la autonomía de la mujer, en lugar de incidir en la necesidad de fomentarla mediante medidas sociales.

Mientras el Consejo de Estado no acaba de contemplar el aborto desde esta perspectiva social, la nueva regulación recién aprobada apunta a la necesidad de hacerlo. A ello han contribuido los debates suscitados por algunos de los puntos más controvertidos de la ley. Me refiero en concreto a la capacidad de las mujeres de 16 y 17 años de consentir autónomamente a la práctica del aborto. Con ocasión de este debate la ciudadanía y nuestros representantes hemos tenido la ocasión de discutir la importancia de garantizar la autonomía y la capacidad de las mujeres gestantes de decidir sobre su embarazo, de apreciar la autonomía de las menores y de garantizarla incluso frente a presiones familiares. Pero también se nos ha dado la ocasión de reflexionar sobre el papel crucial que el entorno familiar juega en la toma de decisiones vitales de tanta importancia como la opción entre aborto y maternidad, lo que conecta con el papel también crucial que dicho entorno desempeña en la educación sexual y reproductiva de niñas, niños y adolescentes. A ese debate contribuyó el Consejo de Estado con una propuesta ponderada, posteriormente acogida por el Parlamento, que abre la interrupción del embarazo de mujeres de 16 y 17 años al conocimiento, pero no a la autorización, de al menos uno de sus representantes legales, siempre que la menor no alegue fundadamente que ello provocará una situación de conflicto familiar grave. Esas reflexiones han sido un elemento importante en la toma de conciencia de la multiplicidad y la complejidad de las relaciones sociales e interpersonales que se dan cita en la problemática del aborto.

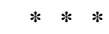


TITLE: ¿A matter of rights? Council of State and abortion.

ABSTRACT: The approach to abortion recently adopted by Spanish law has important gender implications. It articulates the transit to a system that prefers prevention over repression, information over criminalisation and the harmonisation over the confrontation of the interests of pregnant women and unborn life. While the Report issued by the Spanish Consejo de Estado on the new legislation assumes the logic of prevention, it remains committed to the logic of confrontation that lies behind repressive approaches to abortion. The new preventive strategy requires, however, that the confrontational logic be abandoned and that the interests of pregnant women and unborn life be harmonised. This requires that the state alleviates the burdens pregnancy and parenthood place on women and distributes them among men, women and society at large.

RESUMEN: El cambio de perspectiva que introduce la nueva regulación del aborto en España es tan profundo como sus implicaciones de género. Con el tránsito de un sistema de indicaciones a uno de plazos, la represión, el derecho penal y la confrontación de derechos ceden protagonismo a la prevención, la información y la apuesta por proteger la vida del feto mediante el respeto de la autonomía de la mujer gestante. En su dictamen sobre la nueva regulación del aborto, el Consejo de Estado asume en principio la apuesta por la prevención, pero no logra desprenderse de la lógica conflictual propia de planteamientos represivos. Para que la estrategia preventiva sea efectiva es sin embargo necesario que nuestros operadores jurídicos renuncien a dicha lógica y asuman el compromiso de articular un Estado social amable con la maternidad y la paternidad

KeY wORDS: Abortion. Criminalisation. Education. Prevention. Autonomy. Welfare state.

Palabras clave: Aborto. Criminalización. Educación. Prevención. Autonomía. Estado social. 